\title{
The Debate Between Liberalism and Neo-Leftism at the Turn of the Century
}

Chen Lichuan

\section{(2) OpenEdition \\ 1 Journals}

Electronic version

URL: http://journals.openedition.org/chinaperspectives/417

DOI: 10.4000/chinaperspectives. 417

ISSN: 1996-4617

\section{Publisher}

Centre d'étude français sur la Chine contemporaine

\section{Printed version}

Date of publication: 1 October 2004

ISSN: 2070-3449

Electronic reference

Chen Lichuan, «The Debate Between Liberalism and Neo-Leftism at the Turn of the Century », China Perspectives [Online], 55 | september - october 2004, Online since 29 December 2008, connection on 28 October 2019. URL : http://journals.openedition.org/chinaperspectives/417 ; DOI : 10.4000/ chinaperspectives. 417

This text was automatically generated on 28 October 2019

(C) All rights reserved 


\title{
The Debate Between Liberalism and Neo-Leftism at the Turn of the Century
}

\author{
Chen Lichuan
}

\section{EDITOR'S NOTE}

Translated from the French original by Nick Oates

1 From the beginning of the 1980s to the middle of the 1990s, three movements took centre stage on the Chinese intellectual scene: radicalism, conservatism and liberalism. This article sets out to retrace the debate between liberalism and neo-leftism by relying exclusively on the polemical texts of the Chinese writers ${ }^{1}$. How can we present an intellectual debate that is a process of questioning and clarification and that does not arrive at a consensual conclusion? How can we render intelligible the concepts debated in extracts from the original texts? How can we evaluate the impact that this debate has had on a society undergoing a profound transformation? These are just some of the difficulties with which we were confronted. We begin by providing a brief review of how the debate between liberalism and neo-leftism came into being, before comparing, on the basis of some major currents of thought, the writings of the authors who have taken part in the debate. Finally, we explore some tracks of evolution, in particular with regard to a new rift surrounding the question of civil liberties and political democracy.

The rediscovery of liberalism

2 The debate between radicalism and conservatism can be traced back to the beginning of the twentieth century, a time when occidentalists and traditionalists raged a furious dispute. On the cultural level, they clashed in their attitudes to the values of traditional Chinese culture: the former envisaged a scenario of the tabula rasa in which new ideas imported from the West, such as liberty, democracy and progress, would triumph; the 
latter held onto the old values as a system of immutable references that it was necessary to maintain in order to preserve China's cultural identity. On the political level, one side demanded a fundamental change, even if it was to cause a revolution; the other side advocated reform of the current order. In reality, their positions were more complex: cultural radicalism did not necessarily lead to political radicalism, nor cultural conservatism to political conservatism. Hu Shih, the pioneer of Chinese liberalism and indisputable leader of cultural radicalism, was relatively moderate in his political views. Sun Yat-sen, determined revolutionary and committed republican, had a high regard for the ancient political philosophy. Certain men of letters and of politics who were for a time considered radical were later labelled conservatives: Kang Youwei, leader of the Hundred Days' Reform, switched to the conservative ranks after the Republican revolution of 1911; Yan Fu, precursor of Chinese liberalism, finished his career, in the eyes of some, as a defender of Confucian order; and Chen Duxiu, partisan of "total Westernisation" during the May Fourth Movement in 1919 and chairman of the Communist Party following its creation in 1921, became a "man of backward ideas" in the view of intellectuals on the left.

3 For some intellectuals, as Chinese history of the twentieth century oscillated between radicalism and conservatism, what China has lacked is not the impetus to overturn the system in place by force, nor a conservative tradition addicted to the past and advocating the maintenance of the old order, but a liberalism based on pluralism, democracy and the rule of law. Confident in the establishment of this fact, liberalism has, in the course of the twenty-five years of the opening-up of the economy and of social change, experienced an indisputable renewal. Referring to Karl Popper's criticism of scientific analysis, Xu Jilin ${ }^{2}$ asserts, for example, that throughout the twentieth century in China, the intellectual world and socio-political practices gave priority to utopian undertakings for social change (utopian social engineering) in a stepby-step process (piecemeal social engineering) ${ }^{3}$. To a certain degree, the debate between radicalism and conservatism paved the way for a rediscovery of liberalism, a current of thought of Western origin, the implantation of which in China has long been suffocated by a tradition too firmly anchored in collectivism.

4 The other distinctive trait of liberalism is its role as spiritual heir to the New Enlightenment movement, which embodied in the 1980s the new modern culture in the face of socialist tradition and Maoist dogma. There were a great many intellectuals who came together at that time under the flag of the New Enlightenment to break the ideological taboos. In the early stages, numerous intellectuals-the well known and the less well known-took this side in the debate that set radicalism against conservatism, whether in mainland China or overseas. Among them were Yu Yingshi ${ }^{4}$, Jiang Yihua ${ }^{5}$, Wang Yuanhua ${ }^{6}$ and Li Zehou ${ }^{7}$. In the fashion of the latter two, some intellectuals who took part in the New Enlightenment movement in the 1980s have revisited their position and converted to cultural conservatism since $1989^{\circ}$.

5 Indeed, following the tragedy of 1989 , several factors have emerged to modify the positions adopted-on both sides of the debate-on the model of development and the question of reform. These factors have included the difficulties of the transition in Eastern Europe, the implementation of the market economy in China and the strong economic growth that has accompanied it. In this new context, the liberals wish to continue the unfulfilled task of the New Enlightenment by expanding the battle into the terrain of the rights of the individual, while several currents of thought march 
under the banner of "neo-conservatism": neo-Confucianism which, relying on the model of East Asia (Singapore in particular), preaches a return to the system of traditional values; a strengthened statism that devotes itself to the primordial task of maintaining order and stability; and finally, a nationalism that, nourished by frictions with Western countries and inflamed more by an identity crisis than any patriotic fervour, tilts at the United States as an imaginary enemy. For Yang Chunshi ${ }^{9}$, neoconservatism reveals two major weaknesses of contemporary Chinese intellectuals. The first is their immutable attachment to tradition, to which they return to to take refuge in as soon as their struggle-none the less fierce-against this very same tradition meets with failure. The second is their inveterate dependence on the political system: as soon as they lose its support, they recant and sink into bitter defeatism ${ }^{10}$.

The emergence of neo-leftism

6 In 1991, Wang Shaoguang ${ }^{11}$ published an article entitled "Founding a powerful democratic country"12, a text that marked the emergence of neo-leftism on the intellectual scene. Examining the role of the state in the transitional phase towards the market economy, the author demands that this economy be subject to regulation by the state and society. Moreover, he criticises the laissez-faire approach of liberalism and attempts to shatter the myth of the market, as he insists on the necessity of promoting political and economic democracy in order to better lead the reform. But we have to wait until 1994 to see the term "neo-leftism" appear in the Peking and Hong Kong press. Its first accepted meaning describes a group of young intellectuals whose discourse, largely inspired by the Western human sciences, differentiates itself from that of Marxism-Leninism.

7 Neo-leftism enters the second phase of its offensive with the publication in 1997 of an article by Wang Hui ${ }^{13}$ : "Contemporary Chinese Thought and the Question of Modernity" ${ }^{14}$. Examining the direction taken by Chinese modernity, the author seeks to describe the situation in China on the chequerboard of global capitalism. If the neoconservatives insist on the question of the rhythm of reform, advocating moderate progressivism over radical change, it appears that the neo-leftists, for their part, are more preoccupied with the question of the direction in which the reforms are heading. As a result, a lively intellectual debate pits neo-leftism against liberalism. Although neither side constitutes a coherent and homogenous school of thought, they are clearly distinguished from each other by their philosophical, economic and social visions.

Zhu Xueqin ${ }^{15}$ puts forward a definition of what he understands by liberalism: "It is first of all a theory, then a realist claim. Its philosophical conception is empiricism as opposed to apriorism; its historical conception, contrary to any kind of historical determinism, originates from the evolutionist theory likely to eliminate errors; its reformist vision is dependent on a moderate progressivism that prefers gradual expansion and evolution to the artificial construction of radicalism. At the economic level, it calls for the market economy over the planned economy; at the political level, it calls for representative and constitutional democracy and the rule of law, while opposing the dictatorship of a single person or of a minority just as much as the dictatorship of the masses exercised in the name of the general will; at the ethical level, it calls for the guarantee of the irreducible value of the individual, which cannot be sacrificed, in contrast to other reducible values, as an instrument for whatever abstract goals it may be" ${ }^{16}$. 
9 If the liberals show no hesitation in describing themselves as such, the majority of the authors of neo-leftism have never explicitly accepted this label that has been stuck on them by reference to the old orthodox left of the Communist Party. Wang Hui talks of a "set of critical thought" that is occupied with "revealing the relationship between the political and the economic"17. In 1999, Gan Yang ${ }^{18}$ suggested naming the two antagonistic currents of thought, both resulting from the division of the chinese intelligentsia of the 1990s, "the liberal left" and "the liberal right", or even "neoleftism" and "neo-rightism". By reference to the United States of America of today, he comes to the judgement that "the liberal left" is identified more with the liberals, "the liberal right" is more closely related to the conservatives. This is just to say that Gan Yang does not let the Chinese liberals monopolise the definition of liberalism. He seeks to establish a blood bond between neo-leftism in China and liberalism in the West, while deducing from this fact that the debate between liberal left and liberal right is being played out within the framework of the debate between liberalism and conservatism taking place in the contemporary West ${ }^{19}$. This analysis by Gan Yang is disputed by Ren $\mathrm{Ze}^{20}$. who demonstrates point by point, author by author, that the ideas of neo-leftism do not correspond to the American "New Deal Liberalism" of James Tobin and Kenneth Arrow ${ }^{21}$. For his part, Qin Hui ${ }^{22}$, one of the privileged targets of neoleftism, positions himself on the common ground shared by liberalism and social democracy ${ }^{23}$. Against this background, he recalls that even the members of the Conservative Party in Great Britain pass severe judgement on Chinese policy with regard to workers who have been laid off; and that it is not only members of the Labour Party but also conservatives who find it hard to imagine how little social protection Chinese peasants enjoy. In reality, there is nothing paradoxical about resorting to the theory of social democracy to criticise the ultra-liberals and in using the theory of liberalism to criticise the ultra-leftists ${ }^{24}$.

Divergence: the essential points

The first juncture at which liberalism and neo-leftism diverge concerns individual liberty. Of all the priorities, this is considered by the liberals as core. As a consequence, the protection of the right to own private property is a primordial condition both for guaranteeing individual liberty as well as for furnishing a legal framework that is indispensable for the development of the market economy ${ }^{25}$. It was the liberals who proposed adding to the Chinese constitution the clause invoking private property rights, an amendment finally adopted in March 2004 during the tenth plenary session of the National People's Congress. If the neo-leftists did not explicitly oppose the insertion of a clause relating to the protection of private property rights in the Constitution, they have expressed their suspicions about the goal behind this step. On this subject, Wang Hui writes: "Nowadays, hopes are placed on the legitimisation of private property rights as a way to resolve social conflicts. However, if the process of privatisation is not democratic and equitable, this process of legitimisation only serves to protect the process of illegal distribution" ${ }^{26}$. Wang Hui has no difficulty in justifying his remark on the strength of certain consequences of the reform, including abuses of power that have allowed certain individuals to unduly appropriate social assets.

11 The other fundamental divergence that sets the liberals and the neo-leftists in opposition to each other concerns their analyses of Chinese society today. For the neoleftists, this is already a market society integrated with transnational capitalism: "Every day, the market economy becomes more and more the principal form of the 
economy. The economic reform of socialism has led China to production relations within the framework of global capitalism. In conformity with the process of capitalisation, the State and its function have been significantly, if not completely, changed"27. Still according to Wang Hui, the New Enlightenment "was not able to understand in any depth that China's problems are at the same time part of the problems of the global capitalist market. Consequently, China's problems must be diagnosed at the same time as the problems of capitalism as it marches towards globalisation"28.

$\mathrm{Xu} \mathrm{Youyu}^{29}$, one of the liberals' star performers, refutes the approach of the neoleftists, which, according to him, commits an error of judgement: "The diagnosis and the critical judgments that the neo-leftists and the Western neo-Marxists have come to concerning contemporary capitalism can only be applied to China if one considers the nature of Chinese society to be capitalist". Now "we think that Chinese society has undergone great changes, but the nature of that society and its political system are direct descendants of the society and the system that was founded in 1949 and that has passed through the 1950s, 1960s, 1970s and 1980s without revolution or rupture, nor qualitative change" ${ }^{30}$. Nor does Qin Hui accept that neo-leftism should confuse Chinese society with Western society; the latter suffers perhaps from an excess of laissez-faire and the welfare state, but China, in contrast, requires more laissez-faire and more of the welfare state ${ }^{31}$. Is China today a market society? The responses to this question that are given by liberals and the neo-leftists are certainly different, but all agree on the teratological dimension of Chinese society, the avatar of both a very irregular market economy and a political authoritarianism still capable of doing harm.

The third divergence, which holds a very important place in the debate, has to do with social justice. On this terrain, the neo-leftists present themselves as defenders of the victims of the growth in inequality, of widespread corruption, savage redundancies, in short, all the evils let out of the Pandora's box that is the market economy. Liu Qing ${ }^{32}$ sees fit to remark that "when neo-leftism criticises the model of development supported by the Chinese liberals, it never mentions the demand of the market vis-à-vis the political system. The current debate is far too content to examine social justice from the viewpoint of the economy, of capital and of the market, while disregarding the role of the political structure and the intervention of the citizens in political matters, in particular through their participation in the system of the distribution of social assets. If one wishes to criticise the model of liberalism, one has at least to be aware that political liberalism cannot be disassociated from this model" ${ }_{33}$. For Xu Youyu, the liberals are the first to demand social justice. The complexity of the problem relates rather to the fact that power lies at the origin of corruption, but the struggle against it cannot be fought without the co-operation of that power. In the long term, the real remedy consists in creating a market economy where there is fair competition, in guaranteeing the freedom of the press so that public opinion can exercise a checksand-balances role with regard to power ${ }^{34}$. Ji Weidong ${ }^{35}$ underlines the fact that in China, the political system is characterised by an omnipotent power in collusion with the forces of money; in such a configuration, reinforcing the power of the state can only aggravate social injustice. It is necessary first of all to change the nature of that power before implementing economic democracy with the aid of a strengthened power ${ }^{36}$. Zhu Xueqin, for his part, distinguishes what one can and what one cannot ascribe to the market economy: as the market is subject to the goodwill of the regime, the sins of the market economy, whether they be social injustice or collusion between power and 
international capital, are committed more by "the brutal foot" (manheng de jiao) of the regime than by "the dirty hands" (angzang de shou) of the market. "The visible foot walks over the invisible hand", this is the Chinese reality ${ }^{37}$. Zhu reproaches the neoleftists for unrelentingly attacking "the invisible hand" of the market economy without paying the slightest attention to the "visible foot" under which it is being trampled"

The fourth divergence concerns the role that the construction of a market economy may play in the process of political democratisation. The liberals consider that although the market economy does not necessarily lead to democracy, it remains no less a necessary condition for that; in the history of the modern world there is no example of a stable democracy that does not have a market economy ${ }^{39}$. This idea implies a certain hope that we will see the advent of a democratic regime in China as the result of a liberal economy. Li Shenzhi, leader of the liberal intellectuals in spite of himself, has placed his hope in "the normative economy leading to normative politics" ${ }^{40}$. Wang Hui replies that it would be utopian to believe that equality, justice and democracy, both in China and abroad, will be automatically established via the market ${ }^{41}$. Han Yuhai ${ }^{42}$, another figure emblematic of neo-leftism, adopts an even more virulent tone: "On the path to slavery, the liberalisation of capital reinforces the privileges of the class that is already privileged, allowing slavery to grow, and not democracy"43. One might say that this divergence is born above all from the fact that China's economic modernisation, desired by the liberals but contested by the neoleftists, has not been assimilated culturally or politically, but has simply been accepted, even demanded, by the Communist Party as a necessary means for the economic development of the country and the maintenance of its hold on power.

Beyond their disagreements, do liberalism and neo-leftism represent two sides of the same coin? In both camps, certain polemicists attempt to summarise the essence of their divergences in a spirit of reconciliation. Gan Yang considers that "the liberal left" places the emphasis on democracy and equality, while "the liberal right" insists on the primacy of liberty ${ }^{44}$. But for neo-leftism, the question is above all one of economic equality, that is egalitarianism, and not of the equality of everyone before the law, as Chen Yan rightly highlights in his remarkable work, L'Eveil de la Chine: “The principal authors of neo-leftism aim more at equality in the distribution of assets than at equality in law. They show themselves to be more vigilant about the inequalities in income than about the equality of opportunities or the equality of the conditions of which Tocqueville talked" ${ }^{45}$. Han Yuhai recognises that the liberals primarily care about the equity of the distribution of assets, convinced that the free and transparent competition of the market is the only path possible for guaranteeing equity, while the neo-leftists worry above all about the inequitable result of the redistribution of those assets, rising up against the concentration of wealth in the hands of a minority, persuaded that democracy and justice should not be reduced to the free competition of the market ${ }^{46}$. For Zhu Xueqin, neo-leftism primarily denounces the mechanisms of the market economy, while liberalism demands above all reform of the political system ${ }^{47}$. Ren Ze proposes drawing a demarcation line between "economic liberalism" and plain old liberalism, for certain extreme expressions of economic liberalism, such as the corruption that has its reasons and its benefits, do not conform with the theory of liberalism ${ }^{48}$. Xiao Gongqin ${ }^{49}$, for his part, distinguishes the post-modern and social democratic neo-leftists from the populist neo-leftists. The former, mindful of the social policy to be conducted, represent a moderate and constructive force, the latter, 
crystallising an anti-Western nationalism and revolutionary Jacobinism, are radical and dangerous ${ }^{50}$.

Can Chinese modernity detach itself from capitalism?

With the concept of modernity having been forged in and tested against the historical trajectory of the West, the process of modernisation is frequently identified with the advent of the capitalist system. Can China, in the course of its modernisation, avoid the setbacks that Western capitalism has encountered in the historical trajectory of its development? This is a question that preoccupies the neo-leftists. Their ambition is to conceive a Chinese modernity that is distinct from the Western capitalist model.

In the 1980s, the New Enlightenment movement considered socialism as a practice that ran contrary to modernity. Even at the heart of the Communist Party, certain highranking officials, prisoners of its ideological straitjacket nonetheless, tried to rehabilitate modern capitalism. Xu Jiatun ${ }^{51}$ was a notable case in point with his famous article entitled "Rediscovering capitalism, reconstructing socialism" 52 . The liberals of the 1990s were convinced that liberalism was the only path that Chinese modernity could take. Ren Jiantao ${ }^{53}$ lists three positive contributions of liberalism: its mode of the effective accumulation of social assets, through which it can contribute to the economic construction of China and enable the question of poverty to be resolved; its mode of political organisation, through which liberalism can help China liberate itself from a totalitarian and authoritarian system; and finally, as a mode of tolerant thought, liberalism can facilitate the blossoming of a rich and diverse scientific and intellectual life ${ }^{54}$.

18 Ji Weidong, for his part, makes a plea to implement the choice of the liberal system by posing three questions from a comparative point of view: is the liberal system better or worse than other political systems? Is the fundamental problem in China the excess of liberalism and pluralism or the lack of restrictions placed on the power of the state and the predominance of collectivism that leads to the pushing back of individuality and desiccates public life at its source? Can the liberal system moderate or deal with its internal contradictions? ${ }^{55}$.

19 As for neo-leftism, it does not condemn en bloc the practices of Maoist socialism, but tries to justify them by underlying its modernity. Thus Wang Hui explains: "Chinese Marxism is itself an ideology of modernisation. Not only does the Chinese socialist movement hold modernisation to be the fundamental objective, but it embodies the principal characteristic of Chinese modernisation". Or even: "The socialism of Mao Zedong is presented on the one hand as an ideology of modernisation, on the other as a criticism of the capitalist modernisation of Europe and the United States... The socialist thought of Mao Zedong is to some extent a theory of modernity set against capitalist modernisation" 56 .

20 Another way of thinking that is very much in vogue at the moment is described by $\mathrm{Xu}$ Youyu as combinative: it is economically liberal, culturally conservative, politically nationalist and statist. In practice, that leads to the consideration of corruption as the oil that greases the market economy, to the re-evaluation of Confucian authoritarianism and to the support of the powers that be by cultivating nationalist sentiments. Xu Youyu calls for vigilance if this should be the path that China takes ${ }^{57}$.

21 After the fashion of Confucius, who preached the taking of the middle road in a world inclined to dualism, Xu Jilin, Zhang Rulun ${ }^{58}$ or even Luo Gang ${ }^{59}$ launch an appeal for the search for a third way. Xu Jilin praises both the conviction of the liberals who believe in 
the universality of human rights and the moral courage of the neo-leftists who defend social justice. But he reproaches the liberals for forgetting the Chinese context in order to promote privatisation and property rights (which comes down, on the theoretical level, to accepting the whitewashing of money for those who hold a monopoly on power and appropriate for themselves the assets of the state). At the same time, he accuses the neo-leftists of wishing for the direct democracy of the masses in order to find a remedy for social injustice, which seems to him simplistic and dangerous as a method. According to $\mathrm{Xu}$, it is not possible to envisage the large-scale participation of the masses without inviting the risk of a populist outburst, as happened during the French Revolution, the Russian Revolution and the Cultural Revolution in China ${ }^{60}$. Taking the example set by Anthony Giddens, the author of The Third Way - The Renewal of Social Democracy, Xu Jilin uses it to develop between liberalism and neo-leftism an intermediate force focusing equal attention on liberty and social justice ${ }^{61}$.

Zhang Rulun, referring to the social democracy that was advocated by Zhang Dongsun $^{62}$, Zhang Junmai ${ }^{63}$ and Chu Anping ${ }^{64}$ in the 1930s, calls for us to follow "this third path" between capitalism and socialism: "Political democracy and economic democracy must work as a pair, like the two wheels of a cart and the two wings of a bird. Without economic democracy, political democracy will lose its fundamental meaning; without political democracy, economic democracy could not be guaranteed" ${ }^{65}$.

The notion of the third way also lends itself to other interpretations. For Qin Hui, if a third way does exist for China, it will not be found either outside of liberalism and social democracy, nor between the two, but will have to be constructed on the common ground that they share. "The current problem in China is neither equality shackled by too much liberty, nor liberty shackled by too much equality. From this fact, we can only search for the third way that ends in both more liberty and more equality". What China needs therefore, emphasises Qin Hui, is more laissez-faire and more welfare state, exactly the opposite of "the third way" of Anthony Giddens and of Tony Blair ${ }^{66}$.

Tao Dongfeng ${ }^{67}$ comes up with yet another conception for the third way. Starting from the assertion that conservatism and radicalism are defined in China not solely by their attitude towards Chinese culture, but also their attitude towards Western culture (Chinese culture as substance, Western culture as an attribute or even total Westernisation), he accuses cultural conservatives of being essentially nationalist while reproaching the radical liberals for disregarding the plurality of liberalism. He finds it regrettable that the strong tension between conservatism and liberalism traversed twentieth century China without engendering a conservative liberalism in the mould of an Edmund Burke in England, an Alexis de Tocqueville in France or a Friedrich Von Hayek in the United States. This conservative liberalism that he prays for is distinguished from Chinese conservatism on the one hand in so far as it does not defend the tradition of despotism and considers individual liberty as the highest of all goals, and is differentiated from radical liberalism on the other hand through its opposition to the revolution against tradition, for, in a country like China, it is almost impossible to re-establish authority once the traditional authority has been destroyed ${ }^{68}$.

By way of conclusion

25 If ideological and social crises do not immediately give rise to a new political thought, they do not fail to leave a mark on the spirits that live through them and to reveal the 
difficulties with which society is confronted. In fact, the debate between liberalism and neo-leftism is being played out against the background of strong economic growth, the collusion between power and the forces of money, widespread corruption, burgeoning disparities between a majority of poor and a minority of rich, and the contradiction between a poorly regulated market economy and a still-dictatorial political system. Once more, the smell of burned bridges can be distinguished, a problem recurrent throughout the history of modern China. For some, even if they do not admit it openly, while Western society has passed from despotism to democracy, then from democracy to a society of consumption and leisure, China could well dispense with the democratic stage and propel itself directly into a society of consumption and leisure. They harbour strong doubts that political liberalism is the only path that Chinese modernity has to take.

What is the impact of this debate that pits liberalism against neo-leftism? How is it perceived by the leadership of the Communist Party? Yuan Weishi ${ }^{69}$, quoted by Mao shoulong, describes it as a "storm in a teacup". He considers that the polemicists of both sides, or a majority of them, are researchers or university lecturers who have no ties with either official power or the forces of international politics ${ }^{70}$. Xiao Gongqin asserts that the debate between liberals and neo-leftists is limited to Internet sites or to some intellectual works and periodicals with a small circulation. The exchanges rarely take place face to face. There is little awareness of it among the public. The degree of influence of these intellectuals is much less than that enjoyed by their counterparts in the middle of the $1980 \mathrm{~s}^{71}$.

If the debate pitting liberalism against neo-leftism is playing out within a restricted circle that is too marginal to exert a genuine influence over the short-term developments, one cannot for all that underestimate its repercussions in the medium and long term. This debate is first of all making a contribution to the consolidation of a pluralist intellectual life. The maintenance of order and stability that is judged necessary for the deepening of the reforms by the liberals corresponds just as much to the interests of the pragmatic elite in power as to those of private sector entrepreneurs. The demands of the liberals for a better guarantee of private property rights, free and equal competition and respect for human rights perfectly fulfil the expectations of the nascent middle class, while the insistence of neo-leftism on economic democracy and social justice to the benefit of the most powerless is far from useless if drifts in perspective are to be avoided.

$\mathrm{Hu}$ Jintao, President of the Republic and General Secretary of the Chinese Communist Party, declared during a press conference at the end of the APEC meeting in Bangkok on October 21st 2003: "The policy of reform and of opening-up has engendered in twenty years the phenomenon of the fracture (WW, fenhua) between rich and poor. It is impossible that each reform and opening-up measure should be profitable simultaneously for one billion three hundred million Chinese. Some will profit more, and others less. But the objective that the Chinese government has set for the modernisation process is to permit people to get rich together. The government is determined, as it takes strong measures, to help the poor to lift themselves up, all the while allowing a part of the population to outpace the others on the road to enrichment"72. If the discourse cannot itself perform miracles, it at least translates the care of the Chinese government to maintain a balance between a liberal economy and social justice. As for the thorny problem of political reform, if Western democracy is 
practically excluded, an institutional reform that consists in expanding the scope of political intervention of the citizens is not impossible, and this is perhaps what $\mathrm{Hu}$ Jintao means by the expression "the necessity of enriching the forms of democracy".

In this context, the liberals and neo-leftists compel recognition as two influential pressure groups. The situation seems to be evolving towards a kind of tripartite interaction, and it is possible to interpret in this way the establishment in September 2003 of the Innovation Research Centre of the Chinese government ${ }^{73}$ attached to Peking University. Its mission, according to its director Yu Keping, is to institutionalise the exchanges and the co-operation between university researchers and government officials, to survey and evaluate the experiences of the reforms that have been acquired in all ranks of the government, in order to encourage and disseminate them. The final objective is to contribute to the promotion of the reform of the political system ${ }^{74}$. Taking into account the constraints of the reality (the absence of any genuine opposition parties, of a free media, of an independent judiciary, etc.), this process is not uninteresting, although it forms part of the tradition of royal advisors who cultivate collusion with power. What appears strange is that this research centre has been placed in a university, in this case Peking University, which has as its vocation, in theory at least, the conduct of free research into the truth, and not the provision of advice to whatever government it may be.

It has to be admitted that in China at the moment, two profiles of intellectuals can be drawn, those who wish to play a genuine role in the conception of a free and just society-they can be found just as much in the camp of the liberals as in that of the neo-leftists-and those who, for one reason or another, play a part in reinforcing the power in place. The former, currently called "public intellectuals" (WWWWW, gonggong zhishifenzi), frequently assert themselves in the defence of the civil rights of a population that has been misled; the latter, rarely engaged in intellectual debates or public affairs, are for the most part identified with the pragmatic elite within the system. In the absence of any political pluralism, "the public intellectuals" are called upon to play the role of an opposition ${ }^{75}$. Under the single party dictatorship, "the pragmatic elite" is inclined more to institutional reform, conscious that an institution, however effective it may be in its structure, cannot function forever if it is deprived of democratic legitimacy.

31 The distinction between these two types of intellectuals relates perhaps to their response to a crucial question: how can China escape its ancestral logic-"he who conquers state power by force rules"76? The first group seems to believe, consciously or unconsciously, in the emergence of a civil society. Associating themselves with the general population, they demand, for a tactical reason no doubt, "liberty before democracy", using the examples of Hong Kong and Singapore. The second group is convinced that it is necessary to wait patiently for the Communist Party to be transformed from the inside, for the emergence of a civil society depends to some extent on the tacit consent of the party in power. The current situation can be characterised by this double expectation, where a new scission divides the intellectual world around the question of the relationship between society and politics: the dissociation between private and public space (in other words the distinction between civil liberty and political liberty), or the confusion of these two spaces. On this crucial point in the process of the modernisation of Chinese society, it is high time that liberals, neo-leftists and social democrats find a consensus. 


\section{NOTES}

1. Two reference works provide the historical context for this debate. See Chen Yan, L'Eveil de la Chine. Les bouleversements intellectuels après Mao, 1976-2002, La Tour d'Aigues, éditions de l'Aube, 2002; Zhang Lun, La vie intellectuelle en Chine depuis la mort de Mao, Paris, Fayard, 2003.

2. Professor at the Department of History of East China Normal University, Shanghai. 3. Xu Jilin, "Jijin yu baoshou zhijian de dongdang" (Oscillations between radicalism and conservatism), in Zhishifenzi lichang - Jijin yu baoshou zhijian de dongdang (The positions of the intellectuals - Oscillations between radicalism and conservatism), Changchun, Shidai wenyi chubanshe, 1999, p. 40.

4. Professor at Princeton University.

5. Professor at the Department of History of Fudan University, Shanghai.

6. Researcher at the Institute of Literature of the Shanghai Academy of Social Sciences.

7. Researcher at the Institute of Philosophy of the Chinese Academy of Social Sciences.

8. See Li Zehou, Liu Zaifu, Gaobie geming - Huiwang ershi shiji Zhongguo (Farewell to the revolution - a look back at the China of the 20th century), Hong Kong, Tiandi tushu youxian gongsi, 1997. Wang Yuanhua, Jiushi niandai fansilu (Texts on the retrospective examination of the 1990s), Shanghai guji chubanshe, 2000.

9. Professor at the Department of Chinese Literature at Hainan Normal University.

10. Yang Chunshi, "Xinbaoshouzhuyi yu xinlixingzhuyi" (Neo-conservatism and neorationalism), in Zhishifenzi lichang -Jijin yu baoshou zhijian de dongdang, op. cit., p. 492.

11. Economist and associate professor at the Chinese University of Hong Kong.

12. See Dangdai Zhongguo yanjiu zhongxin luncong (Collection of the Research Centre for Contemporary Chinese Culture) of the Chinese University of Hong Kong, No. 4, 1991.

13. Researcher at the Institute of Literature of the Chinese Academy of Social Sciences.

14. See Tianya (Horizon), September 1997.

15. Professor at the Department of History of Shanghai University.

16. Zhu Xueqin, "1998, ziyouzhuyi xueli de yanshuo" (1998, the philosophical discourse of liberalism), in Shuzhaili de geming: Zhu Xueqin wenxuan (The revolution in the study: selected texts by Zhu Xueqin), Changchun, Changchun chubanshe, 1999, p. 381.

17. See Wang Hui, Sihuo chongwen, Renmin wenxue chubanshe, Peking, 2000, preface, pp. 343-345, pp. 430-432.

18. Former editor-in-chief of La Culture: la Chine et le Monde, currently a researcher at Hong Kong University.

19. Gan Yang, "Zhongguo ziyouzuopai de youlai" (The origin of the Chinese liberal left), in Sichao: Zhongguo xinzuopai jiqi yingxiang (Stream of ideas: Chinese neo-leftism and its influence), Peking, Zhongguo shehui kexue chubanshe, 2003, p. 111.

20. Doctor of economics.

21. See Ren Ze, "Zhongguo de xinzuopai shi ziyouzuopai ma?" (Is Chinese neo-leftism a liberal left?), ibid, pp. 312-328.

22. Professor at the Department of History at Tsinghua University.

23. Qin Hui, "Ziyouzhuyi, shehuiminzhuzhuyi yu dangdai Zhongguo wenti"

(Liberalism, social-democracy and problems in contemporary China), in Sichao: Zhongguo xinzuopai jiqi yingxiang, op. cit., p. 385.

24. Ibid, pp. 389-390. 
25. Xu Youyu, "Ziyouzhuyi yu dangdai Zhongguo" (Liberalism and contemporary China), in Zhishifenzi lichang - ziyouzhuyi zhizheng yu Zhongguo sixiangjie de fenhua (The positions of the intellectuals - Debate on liberalism and the scission among the Chinese intelligentsia), Changchun, Shidai wenyi chubanshe, 1999, p. 417.

26. Wang Hui, "Dangdai Zhongguo de sixiang zhuangkuang he xiandaixing wenti" (Contemporary Chinese Thought and the Question of Modernity), in Zhishifenzi lichang ziyouzhuyi zhizheng yu Zhongguo sixiangjie de fenhua, op. cit., p. 93.

27. Ibid, p. 106.

28. Ibid, p. 118.

29. Researcher at the Institute of Philosophy of the Chinese Academy of Social Sciences.

30. Xu Youyu, "Ziyouzhuyi yu dangdai Zhongguo" (Liberalism and contemporary China), in Zhishifenzi lichang - ziyouzhuyi zhizheng yu Zhongguo sixiangjie de fenhua, op. cit., pp. 428-429. 31. Qin Hui, "Ziyouzhuyi, shehuiminzhuzhuyi yu dangdai Zhongguo wenti"

(Liberalism, social-democracy and problems in contemporary China), in Sichao, op. cit., p. 384.

32. Associate professor at the East China Normal University, Shanghai.

33. Xu Jilin, Liu Qing, Luo Gang, Xue Yi, "Xunqiu disantiao daolu" (In search of the third way), in Zhishifenzi lichang - ziyouzhuyi zhizheng yu Zhongguo sixiangjie de fenhua, op. cit., p. 328.

34. Xu Youyu, “Ziyouzhuyi yu dangdai Zhongguo" (Liberalism and contemporary China), ibid, p. 422.

35. Professor at the Faculty of Law, Kobe University.

36. Ji Weidong, "Rang women lai chongjian zhengzhi gongshi" (Let us find political consensus again), see http://www.tylf.net/xuejie/wangvsji.html

37. Zhu Xueqin, “1998, ziyouzhuyi xueli de yanshuo" (1998, the philosophical discourse of liberalism), in Shuzhaili de geming: Zhu Xueqin wenxuan (The revolution in the study: selected texts by Zhu Xueqin), Changchun, Changchun chubanshe, 1999, p. 397.

38. Ibid, p. 402.

39. Xu Youyu, "Ziyouzhuyi yu dangdai Zhongguo" (Liberalism and contemporary China), in Zhishifenzi lichang - ziyouzhuyi zhizheng yu Zhongguo sixiangjie de fenhua, op. cit., p. 419.

40. See Li Shenzhi, "Quanqiuhua yu quanqiu jiazhi” (Globalisation and universal values), in Fengyu canghuang wushinian - Li Shenzhi wenxuan (Fifty years of upheaval and chasm - Selected texts by Li Shenzhi), Hong Kong, Mingbao chubanshe, 2004, p. 387.

41. Wang Hui, "Dangdai Zhongguo de sixiang zhuangkuang he xiandaixing wenti" (Contemporary Chinese Thought and the Question of Modernity), in Zhishifenzi lichang ziyouzhuyi zhizheng yu Zhongguo sixiangiie de fenhua, op. cit., p. 117.

42. Associate professor at the Department of Chinese Language and Literature, Peking University.

43. Han Yuhai, "Ziben dengyu ziyouhua ma?" (Does capital equal liberalisation?), in Kexue shibao, January 3rd 1999.

44. Gan Yang, "Zhongguo ziyouzuopai de youlai" (The origins of the Chinese liberal left), in Sichao: Zhongguo xinzuopai jiqi yingxiang (Stream of ideas: Chinese neo-leftism and its influence), Peking, Zhongguo shehui kexue chubanshe, 2003, p. 118.

45. Chen Yan, op. cit., p. 233.

46. Han Yuhai, "Xiangyue 98, gaobie 98" (Back to 98, farewell to 98), in Zhishifenzi lichang - ziyouzhuyi zhizheng yu Zhongguo sixiangjie de fenhua, op. cit., pp. 223-224.

47. Zhu Xueqin, "Xinzuopai yu ziyouzhuyi zhizheng” (The dispute between neo-leftism and liberalism), in Sichao, op. cit., p. 262. 
48. Ren Ze, “Zhongguo de xinzuopai shi ziyouzuopai ma?" (Is the new Chinese left the liberal left?), ibid, p. 314.

49. Professor at the Department of History of the East China Normal University, Shanghai. 50. Xiao Gongqin, "Xinzuopai yu dangdai Zhongguo zhishifenzi de sixiang fenhua" (Neoleftism and the division among Chinese intellectuals today, in Sichao, op. cit., pp. 406-414. 51. Director of the Xinhua press agency in Hong Kong from July 1st 1983 to February 12th 1990 , forced into retirement following the events of 1989, Xu Jiatun has lived in exile in the United States of America since May 1st 1990.

52. See Xu Jiatun, “Chongxin renshi zibenzhuyi, zijue jianshe shehuizhuyi” (Rediscovering capitalism, reconstructing socialism), in the revue Qiushi (In search of truth), No. 5, 1988. The article by $\mathrm{Xu}$ Jiatun sparked some sharp critical reactions within the Communist Party and the state apparatus, which are evoked in Xu Jiatun Xianggang huiyilu, (Memoirs of Xu Jiatun in Hong Kong), Vol. II, Hong Kong, Lianjing, 1993, pp. 447-448.

53. Guest researcher at Harvard University.

54. Ren Jiantao, "Jiedu xinzuopai” (Reading neo-leftism), in Zhishifenzi lichang - ziyouzhuyi zhizheng yu Zhongguo sixiangjie de fenhua, op. cit., pp. 212-213.

55. Ji Weidong, "Rang women lai chongjian zhengzhi gongshi" (Finding the political consensus again), see http://www.tylf.net/xuejie/wangvsji.html

56. See Wang Hui, "Dangdai Zhongguo de sixiang zhuangkuang he xiandaixing wenti" (Contemporary Chinese Thought and the Question of Modernity), in Zhishifenzi lichang ziyouzhuyi zhizheng yu Zhongguo sixiangjie de fenhua, op. cit., pp. 88-90.

57. Xu Youyu, "Ziyouzhuyi, Falanke fuxuepai ji qita" (Liberalism, the Frankfurt school and others), ibid, p. 190.

58. Professor at the Department of Philosophy at Fudan University, Shanghai.

59. Professor at the Department of Chinese Literature of the East China Normal University, Shanghai.

60. Xu Jilin, Liu Qing, Luo Gang, Xue Yi, "Xunqiu disantiao daolu" (In search of the third way), in Zhishifenzi lichang - ziyouzhuyi zhizheng yu Zhongguo sixiangjie de fenhua, op. cit., p.

324.

61. Ibid, p. 333.

62. Zhang Dongsun (1886-1973), intellectual and man of politics, partisan of a constitutional monarchy at the end of the Qing dynasty. Professor at several Chinese universities, including Peking University, he founded the Chinese National Socialist Party in 1934 with Zhang Junmai, which he then left in 1946.

63. Zhang Junmai (1887-1969), intellectual and man of politics, professor at Peking University, co-founder of the Chinese National Socialist Party, which changed its name in 1945 to become the Democratic and Social Party. He left China in 1951 to go and live in the United States, where he died in February 1969.

64. Chu Anping (1909-1966?), liberal intellectual, professor at Fudan University, founder and editor-in-chief of the weekly Guancha (The Observer), a liberal intellectual review, created on September 1st 1946, banned on December 25th 1948 by the Nationalist government (Kuomintang). Named editor-in-chief of Guangming ribao (Clarity) on April 1st 1957, he was condemned as a rightist and removed from his duties on November 12th of the same year. He was reported missing in September 1966, right at the start of the Cultural Revolution.

65. Zhang Rulun, "Disantiao daolu" (The Third Way), in Zhishifenzi lichang - ziyouzhuyi zhizheng yu Zhongguo sixiangjie de fenhua, op. cit., p. 343. 
66. See preface by the author, Wenti yu zhuyi: Qin Hui wenxuan (Problems and doctrines: selected texts of Qin Hui), Changchun, Changchun chubanshe, 1999, p. 6.

67. Professor at the Faculty of Chinese Literature of the Capital Normal University.

68. See Tao Dongfeng, "Baoshou ziyouzhuyi: Zhonggguo wenhua jiangou de disantiao daolu" (Conservative liberalism: the third way to establishing Chinese culture), in Zhishifenzi lichang - jijin yu baoshou zhijian de dongdang, op. cit., pp. 475-485.

69. Professor at the Department of Philosophy of Zhongshan University, Canton.

70. Mao Shoulong, "Ziyouzhuyi yu xinzuopai zhenglun zhi pinglun" (Criticism on the debate between liberalism and neo-leftism), in Sichao, op. cit., pp. 379-380.

71. Xiao Gongqin, "Xinzuopai yu dangdai Zhongguo zhishifenzi de sixiang fenhua" (Neoleftism and the division among Chinese intellectuals of today), ibid, p. 422.

72. See Ouzhou ribao (Europe Journal) of October 23rd 2003, p. 16.

73. Zhongguo zhengfu chuangxin yanjiu zhongxin.

74. See the press release of the Central News Agency (Taiwan), dated September 10th 2003, reproduced by Europe Journal on September 12th 2003.

75. As Xu Jilin underlines regarding the formation of a community of intellectuals and of a new form of engagement: "It is precisely this global network of knowledge that can construct a complete meaning for this world and represent a third force outside of power and of capital, that is to say an autonomous and expanding cultural field. It is the foundation of the public commitment of intellectuals". See Xu Jilin, "Some possibilities for committed intellectuals? Specialisation of knowledge, commercialisation of culture and emergence of post-modernism characterises the China of the 1990s", Perspectives chinoises, No. 81, January-February 2004, pp. 16-31. 76. dajiangshan, zuojiangshan or datianxia, zuotianxia.

\section{ABSTRACTS}

Taking as its basis the polemical texts of the adherents of liberalism and neo-leftism in China at the end of the last century, this article presents the main questions that the writers from these two camps address, and attempts to measure the impact of this intellectual debate on the recent evolution of Chinese society. 